\title{
Sero-Prevalence and Associated Risk Factor of Bovine Brucellosis in Borena Zone, Southern Ethiopia
}

\author{
Gelma $\mathrm{D}^{\mathbf{1}}$, Iyob $\mathbf{H}^{\mathbf{1}}$, Alemayehu $\mathrm{M}^{\mathbf{2}}$ and Wubishet $\mathrm{Z}^{1,2 *}$ \\ ${ }^{1}$ Wollega University College of Medical and Health Sciences, School of Veterinary Medicine, Nekemte, Ethiopia \\ ${ }^{2}$ Ministry of Agriculture, Animal Diseases Control and Prevention Directorate, Ethiopia \\ *Corresponding Author: Wubishet Z, Ministry of Agriculture, Animal Diseases Control and Prevention Directorate, Ethiopia.
}

Received: October 18, 2019; Published: October 29, 2019

DOI: 10.31080/ASMS.2019.03.0453

\begin{abstract}
Cross-sectional study was conducted from November 2017 to April 2018 to determine seroprevalence of Bovine brucellosis and associated risk factors in selected District of Borana Zone, Oromia Regional state. A total number of 339 blood samples were collected from extensively managed cattle of Indigenous Borana breed and tested for the presence of brucella antibodies using Rose Bengal Plate Test (RBPT). The Rose Bengal plate test positive sample was subjected to ELISA for confirmation. From 20 RBPT sera samples 16 samples was positive with overall seroprevalence of $4.7 \%$ that was recorded in the area. Among the risk factors abortion history and retain Fetal membrane were found significantly associated with seropositivity with $\mathrm{p}<0.05$. This study indicated that female affected than male from sera prevalence of female $5.6 \%$, in which among 265 females, $(n=15)$ was positive and 74 male, $(n=1)$ was positive with $1.4 \%$ prevalence. The study revealed study districts variation showed highest sero prevalence of $9.0 \%$ at Yabello district, whereas the least (2.6\%) at Elwayya district with significant difference of $(\mathrm{P}=0.028, \mathrm{OR}=6.352)$. Again there was a significant association between abortion history with $(P=0.008, O R=6.25)$ and retained fetal membrane with $(P=0.002,0 R=35.2)$, However there is no statistically significant difference in parity number. In general, the status of disease was not well studied and traditional management system of pastoral community indicates the need of study of brucellosis at area.
\end{abstract}

Keywords: Brucella; Elwayye; Gomole; Risk Factors; Zero-Prevalence; Yabello

\section{Introduction}

Ethiopia is a country with different agroecological zones where considerable populations of livestock are raised. The country is known for its high livestock population, being the first in Africa and tenth in the world. The recent livestock population estimated that the country has $59,486,667$ heads of cattle, $30,697,942$ of sheep, $30,200,226$ of goats, 2,158,176 of horses, 409,877 of mules, $8,439,220$ of donkeys and $59,495,026$ of poultry [1].

It contributes to over $40 \%$ of the value of annual agricultural production. These sectors covers about $19 \%$ of the export earn- ings. However, the product of livestock as food producer in Ethiopia is poor. Meat and milk production annual growth is $1.9 \%$ and $2.8 \%$ respectively which is below the recommended average of $4 \%$ that is needed to feed the growing population. One major constraint to low productivity and mortality of animals in Ethiopia is the presence of different wide spread animal disease in the country. Brucellosis is one which has serious economic and public health impact with low mortality that has not received the attention $[2,3]$.

The disease was caused by bacterial species of the genus Brucella. Bovine brucellosis is usually caused by Brucella abortus, less 
frequently by Brucella melitensis and rarely by Brucella suis. B. abortus is mainly infectious for cattle but occasionally other species of animals such as sheep, swine, dogs, camels and horses may be infected. Animal susceptibility to brucellosis depends on their age, sex and environmental factors [4].

Although Brucella species have a wide host range, in cattle it is characterized primarily by abortion in late pregnancy, frequently followed by fetal membrane retention and endometritis, which may be the cause of infertility in subsequent pregnancies $[4,5,6]$. The disease spread through food and grass contaminated by bacteria and affected animals that shed Brucella through vaginal discharge, milk, semen from males, Artificial Insemination. It is essentially a disease of the sexually mature animal and the predilection sites being the reproductive tracts of males and females, especially the pregnant uterus $[4,6]$. Allantoic factors stimulate the growth of most brucella organisms and these factors include Erythritol, possibly steroid hormones and other substances [7].

Brucellosis is considered by FAO, WHO and OIE as one of the most widespread zoonoses in the world. According to OIE, it is the second most important zoonotic disease in the world after rabies. The synonyms of Brucellosis disease is like: undulant fever, Malta fever, Mediterranean fever, enzootic abortion, epizootic abortion, contagious abortion and Bang's disease in animal and human [8].

The chances of infection is comparatively higher in the groups like veterinarians, dairy farmers, ranchers, slaughter house workers and veterinary laboratory workers who are directly in contact with the cattle than the others [9].

Globally today, developed countries have managed to eradicate Brucellosis, but it is still exists in developing countries such as in Africa, Middle East, Asia, the Mediterranean and Latin America. In Africa particularly in Sub Saharan Africa, the seroprevalence of Brucellosis is estimated to be ranging from $10.2 \%$ to $25.7 \%$. Some countries in Africa Seroprevalence of Brucellosis had been reported to be less than $10 \%$ were Benin $4.3 \%$, Ethiopia $4.2 \%$ and Ghana $6.6 \%[10,11]$.

In Ethiopia, different individual have reported bovine brucellosis was spread in urban, peri urban, highland and some lowland of the country [12-14]. The previous study was intended to look the role of brucella infection in causing abortion and its contribution to productivity loss in breeding female [11]. However, the status of disease in cattle was not well document in study area. More importantly, traditional management system of pastoral community such as, communal grazing, importation of animal from infected Herds; inter mixing their livestock at water points and using single bull for breeding purpose without testing, indicate the need of study of brucellosis in pastoral community. The study was designed to estimate seroprevalence and risk associated with bovine brucellosis in selected district of Borana Zone.

\section{Materials and Methods}

\section{Description of the Study Area}

The study was conducted in Yabello, Elwayye and Gomole districts Borena zone Oromia regional state, Ethiopia (Figure 1). Borana zone is a lowland area with arid and semi-arid climate. The annual mean daily temperature of the area ranges from $19-24 c^{\circ}$. Agro-ecologically Yabello district has lowland and midland areas and capital of Borana zone that, located at $570 \mathrm{~km}$ South of Addis Ababa. It has latitude and longitude of $\left(4^{\circ} 53^{\prime} 24 \mathrm{~N}\right.$ and $38^{\circ} 4^{\prime} 48$ E) and an elevation ranging from 350 - 1857 meter above sea level (masl). The average annual rainfall ranges from $300-700 \mathrm{~mm}$ of which 65\% received from April-June (locally called 'ganna') and remaining 35\% received from September-November (locally called 'hagayya') with considerable spatial and temporal variability in quantities and distribution.

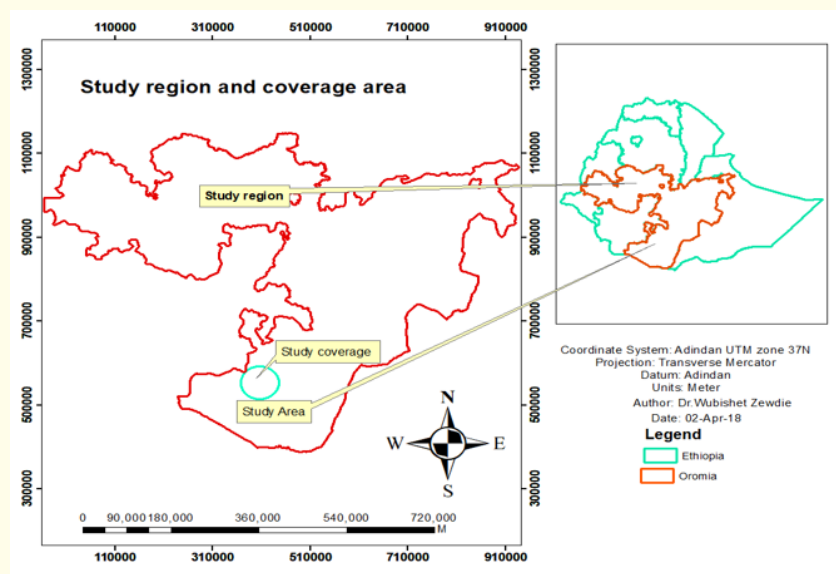

Figure 1: The Map of Study Area, Borana Zone, Yabello, Elwayye and Gomole districts 


\section{Study population}

Population of interest was bovine that managed under pastoral management system for dual purpose. In this study animal Bovine, selected because it is the main milk source of community in study area both for marketing and household consumption [15]. The disease is zoonotic that transmit from animal to human by consuming raw milk and contact with abortion materials. Therefore, Bovine selected to provide information on a disease in study area.

Study design

A cross sectional study was conducted from November 2017 to April 2018 in Yabello, Elwayye and Gomole district of Borana zone, Southern Ethiopia. These districts selected because their accessible for study with few budget. The study design was applied to determine sero-prevalence and risk associated with of bovine brucellosis. From total of 13 districts of Borana zone 3 districts were selected from lowland and midland areas. Elwayye district was from lowland, Yabello and Gomole from midland. The samples were collected randomly from study population and data about age, sex, abortion history and retained fetal membrane recorded from animal attendants or owners while collecting samples.

Sample size determination

A total of 339 samples was initially obtained using 95\% level of confidence interval (CI), $5 \%$ desired level of precision and with the assumption of $10.6 \%$ expected prevalence of bovine brucellosis in indigenous breeds of Borana cattle according to thrusfield [16].

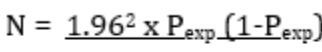

$\mathrm{d}^{2}$

Where:- $\mathrm{N}$ : is required sample size,

$\mathrm{P}_{\text {exp }}:$ is expected prevalence,

$\mathrm{d}^{2}$ : is desired absolute precision.

The sample size was initially calculated by the previous reported prevalence. However, it was doubled for the sake of precision.

\section{Sampling method}

For ease of restraining, sample collection time was preferred to be early in the morning before animals were taken out for grazing. Information of potential risk factors such as sex, age category, district, parity number, Retained Fetal Membrane and husbandry practices was filled out on a developed format during blood collection. Simple random sampling technique was applied for individual animal.

\section{Blood collection}

The blood samples of about $10 \mathrm{ml}$ were aseptically collected by using plain vacutainer tube. The collected samples were labeled with water proof marker. Fanally, colected samples were transported to Yabello regional veterinary laboratory and Serum sample was decanted within 12 hours of collection and stored at $-20^{\circ} \mathrm{C}$ until tested.

\section{Serological method}

Serum samples were allowed to stay 30 minutes at room temperature before being tested, and then serially tested by Rose Bengal plate test using Rose Bengal plate test antigen as presumptive test and by Enzyme Linked Immune Sorbent Assay (ELISA) as confirmatory test at the Yabello Veterinary Regional Laboratory. An animal was considered as positive if tested serum on both RBPT and ELISA serial interpretation show positive reaction. The Rose Bengal plate Test (RBPT) was used as a screening test of serum samples for the presence of Brucella antibody that have a sensitivity of $98.3 \%$ and specificity of $68.8 \%$ [17].

\section{Rose bengal plate test}

Serum samples were screened for Brucella antibodies using the Rose Bengal Plate test. In brief, $30 \mu$ of serum was mixed with an equal volume of antigen suspension on a white enamel plate and agitated. After four minutes of rocking, any visible agglutination was considered as positive [6]. Agglutinations were recorded as 0 , ,+++ and +++ , according to the degree of agglutination. Score of $(0)$ indicates the absence of agglutination; + indicates barely visible agglutination; ++ indicates fine agglutination and +++ indicates coarse clumping. Those samples with no agglutination (0) were recorded as negative while those with,+++ and +++ were recorded as positive. RBPT Brucella antigen (Institute Pourquier, France), positive control and negative control sera were used for the RBPT [18].

\section{ELISA test}

ELISA technique is Biochemical technique used mainly in immunology to detect the presence of an antibody or an antigen. Antibody content of a serum can be assessed by the ability to bind to antigen which has been immobilized by physical adsorption to a plastic tube or micro titter plate with multiple wells. It is a high sensitivity immunotest in which, the antigen or the antibody is adsorbed to a solid surface. The assay was performed in micro titter plastic plates with 96 well, Mostly the antigen is absorbed first to the bottom of the plastic wells. Then, different dilutions of the 
unknown antibody are added to each well. After that the serum containing was added to each well of the micro titter plastic plate.

Data management and analysis

Data generated from laboratory investigation and field information was recorded in a Microsoft Excel spreadsheet, coded and analyzed using SPSS version 20. The hypnotized risk factors also recorded in excel spread sheet for analysis. The hypnotized risk factors, the association of the assumed risk factors and variables (sex, age, district, parity number and history of abortion in herds) for Brucella seropositivity was analyzed by logistic regression analysis. A multivariable logistic regression model was also used to identify association of Brucella infection on above mentioned risk factors.

\section{Result}

The total of 339 serum samples was collected for screening of Brucellosis. All the collected sera were subjected to Rose Bengal plate test and twenty $(n=20)$ sera were found to be positive with the prevalence of $5.8 \%$. Up on further testing of the Rose Bengal plate test positive sera with ELISA, eighteen sera $(n=18)$ became positive. The overall sero-prevalence of brucellosis in study area was $5.3 \%(n=18)$. The seroprevalence of Brucella infection at age, sex and district levels in the study areas was presented by table1.

\begin{tabular}{|c|c|c|c|c|c|c|}
\hline Risk factors & Level & $\begin{array}{c}\text { No of examined } \\
\text { animal }\end{array}$ & $\begin{array}{c}\text { Number of } \\
\text { positive animal }\end{array}$ & Prevalence (\%) & $P$-value & OR $(95 \% \mathrm{CI})$ \\
\hline Sex & Female & 265 & 17 & $6.4 \%$ & 0.121 & $5.004(.655,38.239)$ \\
\hline \multirow[b]{2}{*}{ Age } & 4years and above & 147 & 16 & $10.9 \%$ & 0.25 & $3.82(0.5,39.2)$ \\
\hline & 3-4 years & 99 & 2 & $2.0 \%$ & 0.599 & $1.829(.192,17.393)$ \\
\hline \multirow{3}{*}{ District } & Yabello & 133 & 12 & $9.0 \%$ & 0.01 & $6.45(1.852,41.35)$ \\
\hline & Elwayye & 114 & 3 & $2.6 \%$ & 0.028 & $6.352(1.216,33 \cdot 172)$ \\
\hline & Gomole & 92 & 3 & $3.3 \%$ & & \\
\hline
\end{tabular}

Table 1: prevalence and association of potential risk factors in sex, age and district.

Animals in this study were categorized into three groups, the first group comprising animals with age 1 - 2years with prevalence of $0.0 \%$, second group 3 - 4 years with prevalence of $2.0 \%$ and third groups 4 years and above with prevalence of $10.9 \%$. Age is supposed to have risk, because maturity is very important for the rapid multiplication of brucellosis organisms. The three age groups were compared for seropositivity and there was no statistically significant difference observed in this study with $(\mathrm{P}>0.05)$. However, the age groups above 4 years had the highest seroprevalence that epidemiologically very important in transmission of disease.

The associations of potential risk factors with seropositivity to Brucella infections among selected district were showed by multivariable logistic regression analysis and there was statistically significant difference with $(\mathrm{P}<0.05)$, Yabello a district were high seroprevalence was reported.

Retained fetal membrane was one of the potential risk factors in the study area. A total of 195 cows examined for history of retained fetal membrane, animal with no history of retained fetal membrane was found to be 187 from that, around 13 (7.0\%) animals was found Brucella seropositively, which was less when compared to those with history of retained fetal membrane cows. From 8 animals, 4 were found brucella seropositive with prevalence of (50.0\%). Results of statistical analyzed showed that there was a significant association between retained fetal membrane and seroprevalence of bovine brucellosis with (OR $=35.20 \mathrm{P}<0.05)$ as indicated in Table 2. The risk of animal with RFM was higher in seropositive cows than animal with no history of RFM from the result (Table 2). 


\begin{tabular}{|c|c|c|c|c|c|c|}
\hline Risk factor & Level & $\begin{array}{c}\text { № of examined } \\
\text { animal }\end{array}$ & $\begin{array}{c}\text { No of positive } \\
\text { animal }\end{array}$ & Prevalence & P-value & OR (95\% CI) \\
\hline \multirow{3}{*}{$\begin{array}{l}\text { History of } \\
\text { abortion }\end{array}$} & Anima with HA & 21 & 6 & $28.6 \%$ & 0.008 & $6.25(1.25,35.6)$ \\
\hline & Animal with no HA & 174 & 11 & $6.3 \%$ & 0.07 & $5.9(1.63,21.97)$ \\
\hline & Not concerned & 144 & 1 & $0.7 \%$ & & \\
\hline \multirow{3}{*}{$\begin{array}{l}\text { Retained fetal } \\
\text { membrane }\end{array}$} & Animal with RFM & 8 & 4 & $50.0 \%$ & 0.002 & $35.2(2.14,175.2)$ \\
\hline & $\begin{array}{c}\text { Animal with no } \\
\text { RFM }\end{array}$ & 187 & 13 & $7.0 \%$ & 0.01 & $25.2(1.04,157.1)$ \\
\hline & Not concerned & 14 & 1 & $0.7 \%$ & & \\
\hline
\end{tabular}

Table 2: Multivariable logistic regression models of risk factors like history of abortion and retained membrane.

HA=History of Abortion, RFM=Retained Fetal Membrane.

Parity number of animals has the potential risk factors. The ber increases. However, significant difference in sero-positivity was study showed that there is risk of Brucella infection as parity num- $\quad$ not observed among the three parity groups from the table 3.

\begin{tabular}{|l|c|c|c|c|c|c|}
\hline \multirow{2}{*}{ Risk factors } & Level & $\begin{array}{c}\text { No of examined } \\
\text { Animal }\end{array}$ & No of PA & Prevalence (\%) & P -value & OR (95\%) \\
\hline \multirow{2}{*}{ Parity number } & $1-3$ parity & 71 & 2 & $2.8 \%$ & 0.164 & $7.1(0.44,112.95)$ \\
\cline { 2 - 7 } & 4 and above parity & 108 & 14 & $13.0 \%$ & 0.447 & $2.9(0.180,49.18)$ \\
\cline { 2 - 7 } & Not concerned & 160 & 2 & $1.2 \%$ & & \\
\hline
\end{tabular}

Table 3: Association of parity number with the seroprevalence of bovine brucellosis in selected districts.

$$
\text { Number of positive Animal (PA). }
$$

\section{Discussion and Conclusion}

The present study revealed that an overall Seroprevalence of bovine brucellosis in selected district of Borena zone, Oromia Regional State Ethiopia. The seroprevalence was 5.3\% this report lies between the previous range 4.7 to $10.6 \%$, which reported in Yabello Districts in successive two years [10]. The current overall seroprevalence is comparable with the findings of other authors in Ethiopia $4.6 \%$, and $8.1 \%$ by Yilkal, [3] respectively. Similarly, comparable seroprevalence were reported from other Africa countries; 5.8\% in Nigeria [19], 3.3\% in Central Africa [20]. There was significantly association between Brucella seropositivity and abortion history. The aborted cows were 6.25 times more likely affected than, none aborted cows With $(\mathrm{P}=0.008, \mathrm{OR}=6.25)$.

The present finding was relatively higher with other findings in other parts of the country $1.5 \%$ in shoa, $3 \%$ in the central high lands of Ethiopia, 1.8\% in eastern Amhara Regional State, 1.9\% in and around Shola, 1.5\% in south Eastern Ethiopia, 2.26\% in Sidamo zone as reported [21,22].

In conclusion, the overall seroprevalence of bovine brucellosis in selected district of Borana zone recorded was fall between the ranges of the previous report that conducted in Yabello district. Based on the test result of brucellosis, it is highly associated with history of abortion and retained fetal membrane. In pastorals communities, their management systems expose communities and their livestock to Brucellosis due dailly close contact with discharge of animals and letting it in the field leads both communities and livestock for infection. In future, it may increase the risk infection of different livestock herds per house hold and uncontrolled Movements of animals also increase the spread of the disease. Therefore, The community need to be trained on diseases ways of diseases spread in a herd and to human infection to reduce risk of infection of a disease. 


\section{Bibliography}

1. Central Statistical Agency (CSA). "Agricultural, Report on Livestock and Livestock Characteristics (private peasant holding)". 2 (2017): 37-188.

2. Bekele A., et al. "Bovine brucellosis in ranches and farms in Serosoutheastern Ethiopia". Bulletin of Animal Health and Production in Africa 48 (2000): 13-17.

3. Yilkal A. The epidemiology of bovine brucellosis in inra and peri urban dairy production system in and around Addis Ababa. Master's Thesis, Faculty of Veterinary Medicine, Addis Ababa University, Debrezeit, Ethiopia (1998): 88.

4. Radostits 0., et al. "Veterinary Medicine: a text book of the disease of cattle, sheep, pigs and horses, 9th ed". New York W. B. Saunders Company Ltd (2000): 867-882.

5. World Organization for Animal Health (OIE). "Manual of the diadnostic tests and vaccines for terrestrial animals, 5th Ed". Office International des Epizooties, Paris, France (2004): 409438.

6. World Organization for Animal Health (OIE). "Terrestrial Animal Health Code Brucellosis, science and Comparative Medicine". 12 thedn. Paris, Frane 24 (2011): 69-98.

7. Acha N and Szyfres B. "Zoonoses and Communicable Diseases Common to Man and Animals, 3rded". Vol.1.Pan American Health Organization (PAHO), Washington DC (2003).

8. Mantur G., et al. "Review of clinical and laboratory features of human brucellosis". Indian Journal of Medical Microbiology 25 (2007): 188-202.

9. Corbel MJ. "Brucellosis in humans and animals". Geneva: World Health Organization in collaboration with the Food and Agriculture Organization of the United Nations and the World Organization for Animal Health. Geneva, Switzerland (2006): 1-68.

10. Bekele M., et al. "Seroprevalence of brucellosis and its contribution to abortion in cattle, camel and goat keep under pastoral community". Tropical Animal Health and Production 43 (2011): 651-656.

11. Kubuafor D., et al. "Sera prevalence of Bovine Brucellosis in cattle and humans in the Akwapim-south district of ghana. Public health implication". Acta Tropica 76 (2000): 45-48.
12. Asfaw Y., et al. "A cross sectional study on bovine brucellosis and test performance in intra and peri-urban dairy production system in and around Addis Ababa". Bulletin of Animal Health and Production in Africa 46 (1998): 217-224.

13. Kebede T., et al. "Seroprevalence of bovine brucellosis in smallholder farms in central Ethiopia (Wuchale-Jida district)". Revue de Médecine Vétérinaire 159.1 (2008): 3-9.

14. Dinka H and Chala R. "Seroprevalence study of bovine brucellosis in pastoral and agro-pastoral reas of East Showa zone, Oromia Regional State, Ethiopia". American-Eurasian Journal of Agricultural and Environmental Science 6 (2009): 508-512.

15. De-Lahunta A and Habel E. "Teeth applied veterinary anatomy". W.B. Saunders Company (1986): 4-6.

16. Thrusfield M. "Veterinary Epidemiology". 3rd ed. Oxford: Blackwell Science Ltd. (2005): 228-246.

17. Dahoo., et al. "Brucellosis". The New England Journal of Medicine 352 (2005): 2325- 2336.

18. Mac Millan., et al. "A sporadic outbreak of human brucellosis in Korea". Journal of Korean Medical Science 20 (2005): 941-946.

19. Cadmus SIB., et al. "Seroprevalence of bovine brucellosis in trade cattle slaughtered in Ibadan, Nigeria, from 2004-2006". Journal of the South African Veterinary Association 81.1 (2010).

20. Nakaune E., et al. "Serological surveillance of brucellosis and $\mathrm{Q}$ fever in cattle in the Central African Republic. S.A. Adesida et al./Beni-Suef Univ". Journal of Basic and Applied Sciences 6 (2017): 112-117.

21. Kassahun A. "Epidemiologys of brucellosis in cattle and its sera prevalence in animal health professionals in Sidama Zone". southern Ethiopia (2004): 342.

22. Tadele T. "Sera prevalence of bovine brucellosis and its public health significance in selected sites of Jimma Zone". Western Ethiopia. Mater's Thesis, faculty of Veterinary Medicine, Addis Ababa University, Debrezeit, Ethiopia (2004): 88.

\section{Volume 3 Issue 11 November 2019 (C) All rights are reserved by Wubishet Z, et al.}

